\title{
La cartografía coreográfica: el espacio, el no-lugar y su aporte
}

Francisco Durán-Barrón

Director coreográfico

Compañía de Danza

Universidad Autónoma

del Estado de Hidalgo

México

Recibido. 19 de julio 2019

Aceptado, 19 de diciembre, 2019

DOI: https://doi.org/10.15359/tdna.36-67.2

\section{Resumen}

El presente ensayo analiza y relaciona el no-lugar, concepto desarrollado por Marc Augé, con los espacios contemporáneos de confluencia, su apropiación y la generación de propuestas escénicas, proponiendo el análisis y lectura de estos como actos semióticos para resignificarlos.

Palabras clave: Semiótica, artes, no-lugar, Marc Augé, cartografía coreográfica

\section{Abstract}

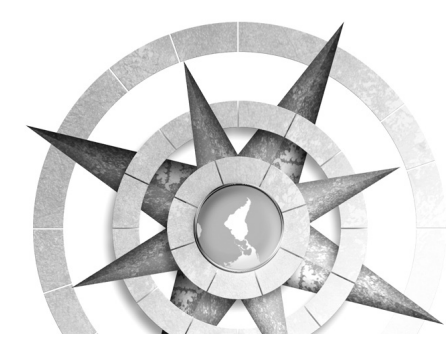

This essay analyses and relates the concept of non-place, developed by Marc Augé, to contemporary spaces of confluence, their appropriation and the generation of performing proposals, suggesting the analysis and interpretation of those as semiotic acts to resignify them.

Keywords: Semiotics, arts, non-place, Marc Augé, choreographic cartography

\section{Resumo}

Este ensaio analisa e relaciona o não-lugar, um conceito desenvolvido por Marc Augé, com espaços contemporâneos de confluência, a sua apropriação e a geração de propostas cénicas, propondo a análise e leitura destas como actos semióticos para as re-significar.

Palavras chave: Semiótica, artes, não-lugar, Marc Augé, cartografia coreográfica 


\section{I}

Construir un texto con la premisa de compartir las ideas que uno encuentra estimulantes nunca es fácil, porque es un arduo compromiso el de poner ideas en las mentes de otros. Sin embargo, tal vez se siembre un detonante: la semilla de la duda. Acepto el compromiso y me doy a la tarea de empezar, esperando sembrar ese detonante. El antropólogo francés Marc Augé definió el concepto de "no lugares" como

lugares de transitoriedad que no tienen suficiente importancia para ser considerados como "lugares". Un no-lugar es una autopista, una habitación de hotel, un aeropuerto o un supermercado, una plaza pública de paso... Carece de la configuración de los espacios, es en cambio circunstancial, casi exclusivamente definido por el pasar de individuos. No personaliza ni aporta a la identidad porque no es fácil interiorizar sus aspectos o componentes. Y en ellos la relación o comunicación es más artificial... Son espacios propiamente contemporáneos de confluencia anónimos, donde personas en tránsito deben instalarse durante algún tiempo de espera y sólo permiten un furtivo cruce de miradas entre personas que nunca más se encontrarán (1992)

Hoy, para estar en este espacio, tuve que instalarme en un par de no lugares hace unos días, habitarlos, construir a partir de fugitivas miradas un tiempo y un espacio, de re-significar lo que me rodea para construirme a cada minuto.

Yo vengo de un no lugar. Es una ciudad que se ha construido a la sombra de la gran metrópoli que es la Ciudad de México, y por esta naturaleza podríamos considerarnos una ciudad de paso. Mi ciudad, desde su fundación en 1560 , sólo fue un lugar minero que no alcanzó el esplendor de ciudades como Zacatecas y Guanajuato (que de igual manera eran mineras), por el simple y siniestro hecho de estar tan cerca de la capital del país. La centralización la perjudicó más de lo que se cree. 


\section{Fotografía 1.}

Se deben analizar y estudiar las lecturas que dan los lugares, y tras este acto semiótico definir si el lugar aporta o minimiza la potencia de la pieza.

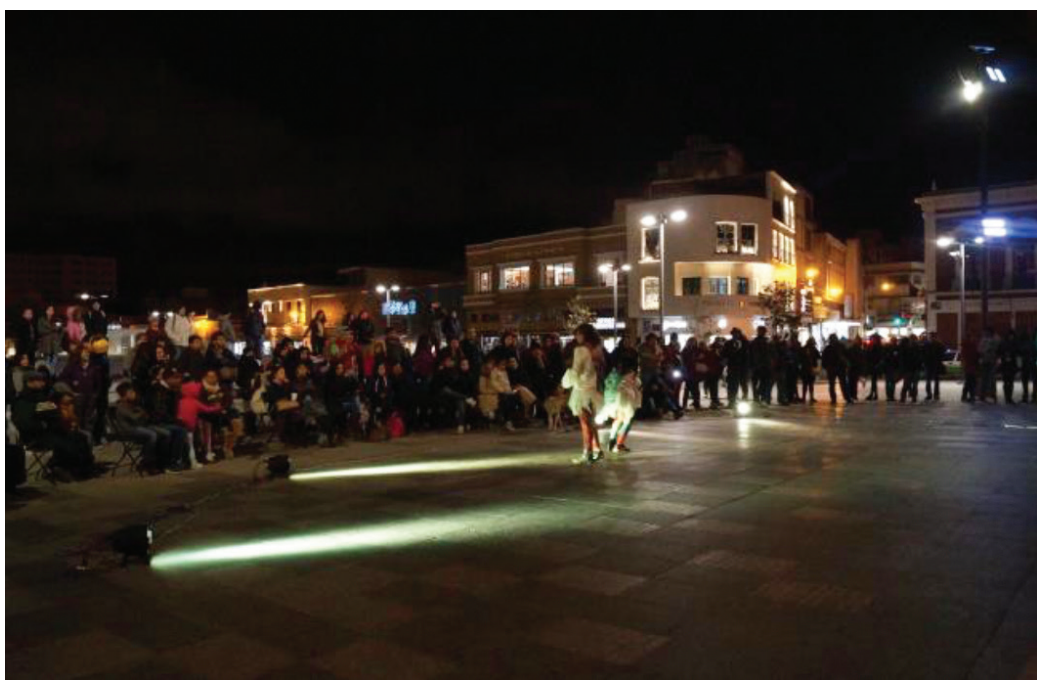

Fotografía: Paco Durán-Barrón

Son espacios propiamente contemporáneos de confluencia anónimos, donde personas en tránsito deben instalarse durante algún tiempo de espera y sólo permiten un furtivo cruce de miradas entre quienes nunca más se encontrarán.

Una ciudad que no permite a los pares encontrarse requiere de la intervención de puentes y la re-significación de los espacios.

Ante tales circunstancias, fue necesario poner manos a la obra, no sólo en la generación de propuestas escénicas que permitirían crear públicos, sino también la creación de ejes y acciones paralelos que apuntalarán el trabajo. Construir de la nada en un espacio que no da nada, pudiera sonar difícil. Y lo es. Convencer, acercarse, invitar, definir, platicar con cientos de personas que no saben para qué apoyar un proyecto o idea, se puede volver el pan de cada día.

Un día decidimos llevar la danza a las calles de mi pequeña ciudad, encontrarnos cara a cara con el tran-seúnte. Fue ir a donde las personas ya estaban, re-significar el no lugar, hacerlo nuestro. 


\section{II}

Las tendencias dancísticas que dejan de lado el uso de los espacios convencionales cada vez son más frecuentes; transformar el espacio escénico también se convierte en una necesidad. De esta labor nace un nuevo papel: yo lo llamo el cartógrafo coreográfico.

Este nuevo ser escénico, y cuyo título evoca la antigua tradición de personajes que dedicaron su vida a elaborar mapas de tierras nuevas, generando rutas, describiendo accidentes geográficos y colocando en algún papel datos que permitirían la exploración y el tránsito de futuros exploradores, es la evolución de lo que hasta hace tiempo considerábamos inmutable: el papel unifuncional del director o coreógrafo.

La intervención de espacios no convencionales no debe tener como naturaleza el mero objetivo de llegar, instalar una bocina y ejecutar el acto dancístico, pues ello es hacer menos al espacio, mini- mizar sus posibilidades. Se deben analizar y estudiar las lecturas que dan los lugares, y tras este acto semiótico definir si el lugar aporta o minimiza la potencia de la pieza. No es lo mismo ver Blush de Wim Vandekeybus en su versión fílmica que en la sala principal del Palacio de Bellas Artes de la Ciudad de México.
Construir un no lugar en un lugar antropológico es una meta insoslayable, entendiendo por lugar antropológico un lugar de encuentro, de cruce.

\section{III}

Susana Sanguineti, investigadora espanola, tiene las palabras precisas:

Pueden ser itinerarios que pasan y recorren distintos lugares de reunión, caminos que conducen de un lugar a otro en los cuales los individuos se reconocen dentro de un espacio que les es propio; encrucijadas donde los hombres se citan; lugares de reunión como los mercados, ciertas plazas, ciertas calles, siempre las mismas, donde bailan los celebrantes espontáneos en carnaval. [...]

Todas estas relaciones que se establecen en el lugar se concretan también, obviamente, en el tiempo... crean una memoria que los vincula con lo sagrado y cuando el participante los recorre, no solo toma conciencia del grupo del cual forma parte sino de las celebraciones precedentes. Las ciudades nuevas no tienen esos lugares animados por una historia antigua, reiterada, más lenta que las que propone la nueva ciudad, sin encrucijadas, sin itinerarios.

24 La cartografía coreográfica: el espacio, el no-lugar y su aporte Francisco Durán-Barrón 
Estas ciudades nuevas terminan construyendo esos lugares de encuentro, esos espacios significativos. Porque el hombre que vive en una comunidad pequeña (generalmente el caso de las ciudades nuevas) es individuo-vecino y como tal y siempre en carácter de hipótesis, gregario en búsqueda del otro que vive dentro de su misma frontera (2007, pag. 14)

En Hidalgo, en mi Pachuca, en esta pequeña parte de mi México donde el fútbol se toma a sorbos y las expresiones culturales muchas veces se miran con desconfianza, decidimos convertir el lugar en espacio apegándonos a esta diferencia que Michel de Certeau hace entre conceptos: el lugar como un espacio geométricamente diseñado por personas cuya visión de urbanidad sólo corresponde a la funcionalidad de los trazos, por un lado, y el espacio en el que los elementos se mueven, por otro, el espacio que se ve lleno de vida con movimiento, permitiendo la interacción de las personas, haciendo suyos los componentes del lugar y re-significando cada uno de ellos, impregnados de sí, de su esencia para, con ello, darle un valor personal.

\section{Fotografía 2}

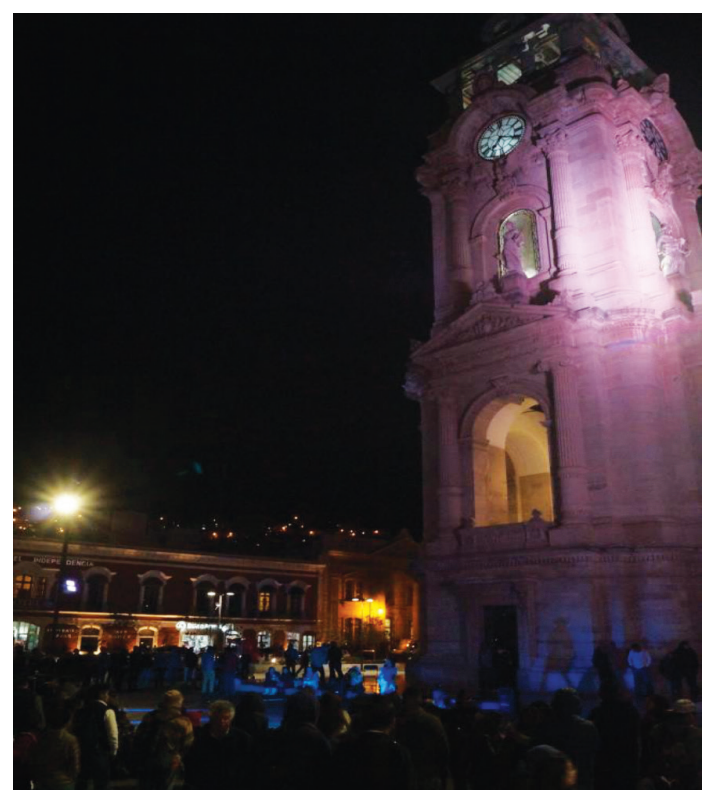

Foto: Cortesía del Festival de Danza Contemporánea Alternativo Hidalgo. 
Salimos a invadir espacios, a encontrarnos con la gente, tratando de que el público, a través de la danza, encuentre en lugares que hasta ahora no for- maban parte de su mapa personal un espacio donde encontrarse con el otro. Tenemos como propósito hacer de Pachuca un lugar fértil para las artes, cambiar la frase "aquí no hay nada" por la frase "aquí está todo".

Al final debo decir que han sido grandes seres, amigos todos, dispersos por todos los rincones los que me hacen creer que esto es posible. Edy Esquivel en Monterey, Nuevo León, Jorge Luis Salazar por Culiacán, Óscar Sánchez, Abil Meneses, Daniel Álvarez en Querétaro, Israel Chavira y Sergio Granados en Morelia, Pedro García, Edna Ar$\cos$ y Luis Vallejo en Xalapa, Diana Venegas en Aguascalientes, Gabriela Montero en Puebla, Melisa Castillo y muchos otros me hacen creer cuando les digo que la danza siempre provee y la danza siempre se abre camino...

\section{Referencias bibliográficas}

Augé, M. (1993) Los no-lugares. Espacios del anonimato. Una antropología de la sobremodernidad. Barcelona: Editorial Gedisa.

(1992). Non-lieux. Introduction a une anthropologie de la surmodenité. Paris: Edition de Seuil.

López Arandia, M. A. (coord.) (2014). Ciudades y fronteras. Una mirada interdisciplinar al mundo urbano. España: Universidad de Extremadura.

Merlos, L.; Sáez, M. (2016). Arte y ciudad: Experiencias de danza en el espacio urbano.

European Review of Artistic Studies 7(3) pp. 65-93.

Sanguinetti, S. (2007). Cuando el no lugar se mete dentro de la casa. Reseña del libro de Marc Augé. Revista Latina de Comunicación Social, No. 62. 